Tohoku J. Exp. Med., 1988, 156, Suppl., 143-149

\title{
Effect of Sleep Position on Obstructive Sleep Apnea
}

\author{
Hiroshi Miki, Wataru Hida, Yoshihiro Kikuchi and \\ Tamotsu Takishima \\ The First Department of Internal Medicine, Tohoku \\ University School of Medicine, Sendai 980
}

\begin{abstract}
Miki, H., Hida, W., Kinuchi, Y. and Takishima, T. Effect of Sleep Position on Obstructive Sleep Apnea. Tohoku J. Exp. Med., 1988, 156, 143-149—_ In order to examine the effect of sleep position on sleep apnea episodes, seven male patients diagnosed as having obstructive sleep apnea syndrome without any organic complication of the upper aiway were studied while lying in a supine or lateral position during an all-night polysomnographic study. Apnea index, apnea time/total sleep time $(\%)$ and the number of episodes per hour in which oxyhemoglobin saturation dropped below $85 \%$ decreased significantly from $51.0 \pm 8.6$ (mean \pm s.D.) events $/ \mathrm{hr}, 40.4 \pm 5.8 \%$ and $36.2 \pm 9.8$ episodes $/ \mathrm{hr}$ during sleep in supine position to $27.6 \pm 9.1$ events $/ \mathrm{hr}, 19.4 \pm 6.0 \%$ and $12.9 \pm 5.3$ episodes $/ \mathrm{hr}$ during sleep in lateral position, respectively. Lowest oxyhemoglobin saturation increased significantly from $70.7 \pm 2.6 \%$ to $78.0 \pm 2.4 \%$. Thus, sleep in the lateral position may be a simple treatment before essential treatment for patients with obstructive sleep apnea syndrome.__ sleep apnea syndrome; sleep posture ; apnea index
\end{abstract}

The possibility of a decrease in upper airway muscle tone in obstructive sleep apnea, has been raised. If resting upper airway muscle tone decreases, posterior displacement of the tongue may contribute to closure of the upper airway in the supine position, compared with lateral position. Therefore, we might expect apnea episodes experienced during sleep in the lateral position to be lessened during sleep in supine position and thus sleep in lateral position may be useful in treatment of obstructive sleep apnea syndrome. However, there have been very few reports concerning the effect of sleep position on sleep apnea syndrome, except for the recent two papers (Cartwright et al. 1985; Mcevoy et al. 1986). In the present study, we compared sleep episodes occurring during sleep in the supine position with those occurring during sleep in the lateral position. We found sleep apnea episodes in the lateral position were significantly reduced in comparison with those in the supine position. Thus, sleep in the lateral position may be a simple effective treatment for obstructive sleep apnea syndrome.

Correspondence to: Tamotsu Takishima, M.D., Professor and Chairman, the First Department of Internal Medicine, Tohoku University School of Medicine, 1-1 Seiryo-machi, Aoba-ku, 980, Sendai Japan. 


\section{Methods}

Subjects

Seven male patients with obstructive sleep apnea syndrome (OSAS), aged between 38 and 63 years were studied. Sleep apnea syndrome was diagnosed according to the definition of Guilleminault et al. (1976). Individual patient data are given in Table 1. None of the seven patients were treated. Six patients were obese (114 to $159 \%$ of ideal body weight). Five patients were hypoxemic and only one had an elevated $\mathrm{PaCO}_{2}$. Five had associated cardiovascular abnormatilies. Apart from obesity, however, there were no other known causes of OSAS present. All patients had normal pulmonary function.

\section{Procedures}

Each subject diagnosed as having obstructive sleep apnea syndrome without any organic complication of the upper airway were participated in examination to see the effect of sleep position on apnea episodes. The patients slept in a complete supine position for two nights during an overnight polysomnographic study. Data taken the first night were not accepted because of the first night effect on sleep episodes. Data taken the second night was accepted. Following the second night of polysomnographic testing, the patients were trained so as to sleep in a lateral position for 5-7 days. To sustain the lateral position, a mat was placed behind the patients' back. The patient then underwent polysomnographic testing in the lateral position for two nights: In the testing nights, the examiners urged the patients to keep the supine or lateral position overnight. If some patients changed position from lateral to supine or from supine to lateral during sleep, the examiners corrected the sleep position to the object position without arousal. The polysomnographic study included standard recordings of electroencephalogram (EEG), electrooculogram (EOG), electrocardiogram (ECG) and submental electromyogram (Rechtschaffen and Kales 1968). Respiration was monitored by measuring nasal airflow with thermistors. Respiratory movement was measured with a inductance plethysmograph (Respitrace, Amburatory Monitoring Inc., Ardsky, NY, USA), continuous arterial oxyhemoglobin saturation was measured with a pulse oximeter (Biox 3700, Ohmeda, Boulder, CO, USA), and tracheal breath sounds were recorded over the cervical trachea (Krumpe and Cummiskey 1980). Tracheal breath sounds were sensed directly by microphone. The sound was high-pass filtered above $200 \mathrm{~Hz}$ to

TABLE 1. Characteristics of patients with obstructive sleep apnea

\begin{tabular}{cccccccccc}
\hline $\begin{array}{c}\text { Patient } \\
\text { No. }\end{array}$ & $\begin{array}{c}\text { Age } \\
\text { (year) }\end{array}$ & Sex & $\begin{array}{c}\text { Height } \\
\text { (cm) }\end{array}$ & $\begin{array}{c}\text { Weight } \\
(\mathrm{kg})\end{array}$ & $\begin{array}{c}\text { Weight } \\
(\% \text { of } \\
\text { ideal) }\end{array}$ & $\begin{array}{c}\mathrm{VC} \\
(\% \text { pred.) }\end{array}$ & $\begin{array}{c}\mathrm{FEV}_{1} \\
(\% \text { pred.) }\end{array}$ & $\begin{array}{c}\mathrm{PaO}_{2} \\
(\mathrm{mmHg})\end{array}$ & $\begin{array}{c}\mathrm{PaCO}_{2} \\
(\mathrm{mmHg})\end{array}$ \\
\hline 1 & 43 & $\mathrm{M}$ & 165 & 69 & 125 & 92 & 101 & 87.8 & 36.5 \\
2 & 61 & $\mathrm{M}$ & 160 & 62 & 109 & 125 & 134 & 68.1 & 39.1 \\
3 & 58 & $\mathrm{M}$ & 166 & 64 & 114 & 90 & 81 & 81.2 & 37.1 \\
4 & 58 & $\mathrm{M}$ & 154 & 78 & 159 & 96 & 104 & 65.5 & 46.8 \\
5 & 38 & $\mathrm{M}$ & 160 & 83 & 151 & 97 & 88 & 73.3 & 35.4 \\
6 & 48 & $\mathrm{M}$ & 161 & 82 & 146 & 84 & 94 & 76.2 & 37.0 \\
7 & 63 & $\mathrm{M}$ & 153 & 57 & 119 & 101 & 103 & 61.9 & 39.3 \\
Mean & 52.7 & & 159.8 & 70.6 & 131.9 & 97.9 & 100.6 & 73.4 & 38.7 \\
S.D. & 9.0 & & 4.5 & 9.6 & 18.3 & 12.4 & 15.5 & 8.4 & 3.5 \\
\hline
\end{tabular}

Predicted values (\%pred.) are those obtained by Cotes JE. Lung function. 3rd ed. Oxford : Blackwell, 1975; 382-6 


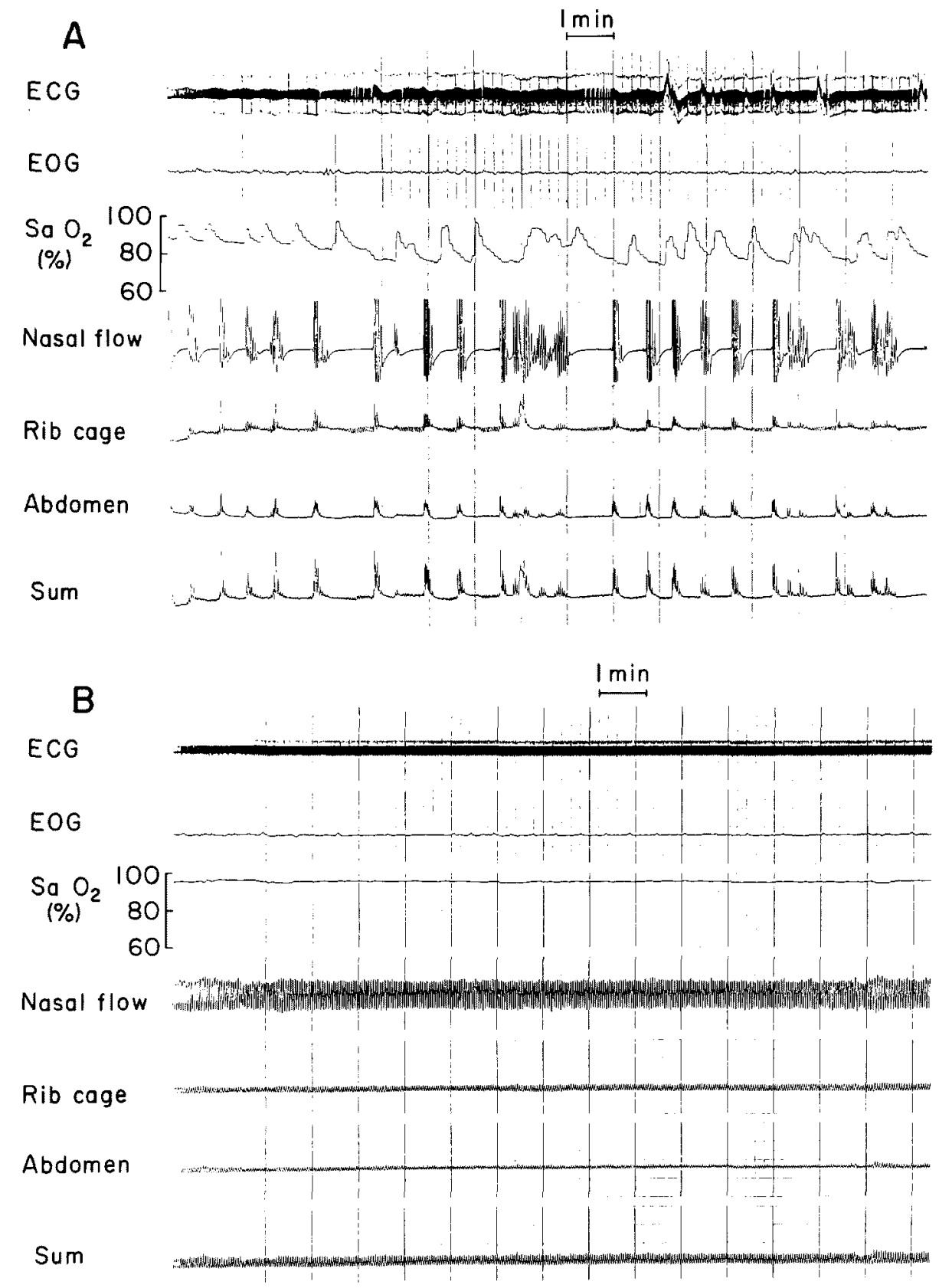

Fig. 1. Typical traces of polysomnography during sleep in the supine position (A) and the lateral position (B). During sleep in the supine position, apnea episodes were observed repeatedly and oxyhemoglobin saturation was also reduced. 
exclude cardiac and vascular sounds. This signal was rectified and integrated to display a sound envelope as previously reported (Cummiskey et al. 1982). The tracheal sound intensity during breathholding was adjusted to baseline as zero flow.

Data analysis

Apnea was estimated to have occurred when both nasal flow and tracheal sound level were zero. Apnea index, apnea time/total sleep time (\%), lowest oxyhemoglobin saturation and the number of episodes per hour that oxyhemoglobin saturation dropped below $85 \%$ $\left(\mathrm{SaO}_{2}<85 \% / \mathrm{hr}\right)$ were obtained. Statistical analyses were performed with the paired $t$-test and values of $p<0.05$ were accepted as significant.

\section{RESULTS}

Fig. 1 shows typical polysomnographic traces obtained during sleep in the supine position (A) and the lateral position (B). These two traces were obtained during non-REM sleep. During sleep in the supine position, obstructive apnea episodes were observed repeatedly and oxyhemoglobin saturation was also reduced during apnea, by the amount from 4 to $27 \%$. However, during sleep in the lateral position, obstructive apnea episodes nearly disappeared.

Fig. 2 shows the trend of the apnea episodes in one patient. During sleep in the lateral position, apnea episodes occurred every fifteen minutes decreased remarkably.

Fig. 3 shows individual apnea index, apnea time/total sleep time, lowest oxyhemoglobin saturation and the number of episodes per hour in which oxyhemoglobin saturation dropped below $85 \%\left(\mathrm{SaO}_{2}<85 \% / \mathrm{hr}\right)$ during sleep in
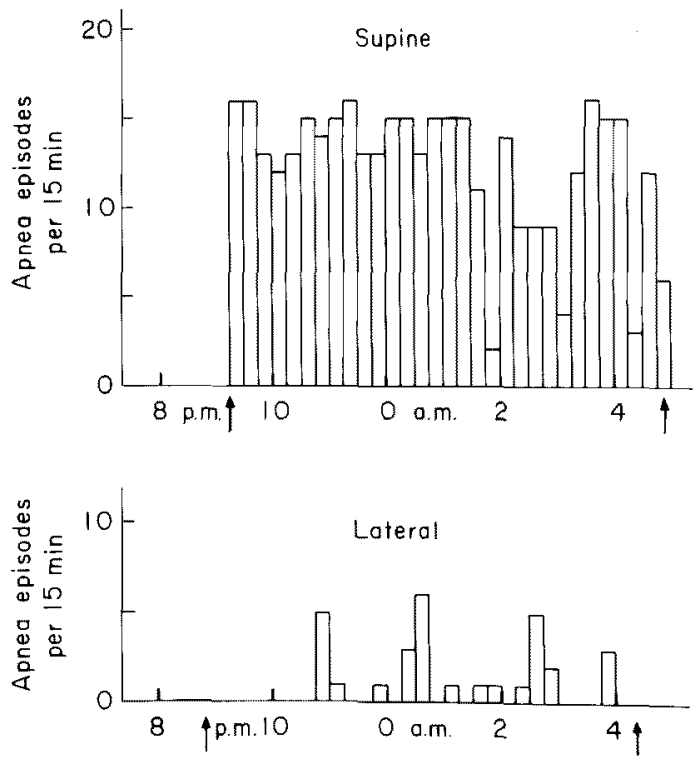

Fig. 2. Trend in apnea episodes per 15 minutes during sleep between arrows in the supine position (upper panel) and the lateral position (lower panel). 

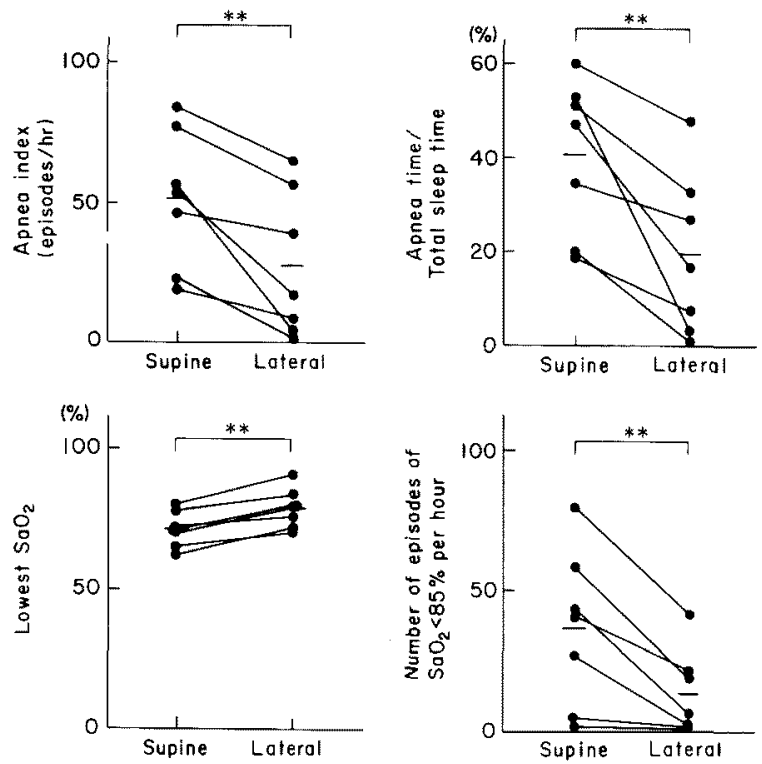

Fig. 3. Effect of sleep position on apnea index, apnea time/total sleep time, lowest oxyhemoglobin saturation and the number of episodes per hour in which oxyhemoglobin saturation $\left(\mathrm{SaO}_{2}\right)$ dropped below $85 \%$. Short horizontal lines represent mean values for 7 patients. All patients showed a reduction of apnea episodes with lateral position. ${ }^{* *} p<0.01$.

supine or lateral position. Apnea index, apnea time/total sleep time and $\mathrm{SaO}_{2}<$ $85 \% / \mathrm{hr}$ during sleep in the lateral position decreased significantly compared with those during sleep in the supine position. Lowest oxyhemoglobin saturation significantly increased in the lateral position. Sleep stage assessed by EEG (Rechtschaffen and Kales 1968) showed no appreciable differences between the two conditions. Thus, all the patients improved obstructive apnea symptom by lateral position.

\section{Discussion}

Various teatment of sleep apnea syndrome have been described. Administration of respiratory center stimulants (Gabriel et al. 1978; Hensley et al. 1980) and antidepressants, uvulopalatopharyngoplasty (Fujita et al. 1981), tracheostomy (Weitzman et al. 1980), breathing due to continuous positive airway pressure (Sullivan et al. 1981) and reduction of body weight have been reported. However, a consistent treatment of sleep apnea syndrome has not been established. Very few studies have been reported in which the effect of sleep position on apnea episodes was examined. We found improvement of apnea during sleep in the lateral position, compared with sleep in the supine position, and sleep in lateral positions seems to be a simple treatment before essential treatment.

Gastaut et al. (1966) and Harper and Sauerland (1978) have observed increased obstructive apnea associated with the supine posture in sleeping adults. 
Furthermore, Cartwright et al. (1985) reported that apneic episodes were reduced during sleep in the lateral position, compared with sleep in the supine position. The present observation has also shown the effectiveness of the lateral sleeping posture in reducing apneic episodes. The reason for the difference in apneic episodes between the two postures was not unclear in the present study, however, we may speculate as follows. Pharyngeal soft tissue such as the tongue and soft palate move posteriorly and are apt to induce obstruction of the upper airway during sleep in the supine position, compared with sleep in lateral position. In contrast, Safar et al. (1959) and Wilson et al. (1980) did not show an effect of gravity on pharyngeal tone in anesthetized subjects and in infants after death. The cause of the discrepancy between those two results is not clear. However, the upper airway configuration during sleep may be differ from that during anesthesia or following death.

Very recently, Mcevoy et al. (1986) compared the apneic episodes during sleep in supine position with those during sleep in the upright position. They found the upright sleep posture lead to a reduction in apneic episodes. Maintaining upright position during sleep is difficult at home, because a specially designed device is necessary.

The lateral position in the present study was forced to take for example by the bedclothes back the patients during sleep. Training to maintain the lateral position during sleep may be appropriate as a simple treatment or in combination with other measure such as weight loss. We examined two additional patients with tonsillar hypertrophy. In these two cases apnea index did not diminish, although the lowest oxyhemoglobin saturation and $\mathrm{SaO}_{2}<85 \% / \mathrm{hr}$ did decrease. These patients later underwent tonsillectomy after which sleep apnea episodes disappeared. Even in patients with organic complications, the lateral posture during sleep apnea prior to invasive therapy may be effective.

\section{Acknowledgments}

We thank Dr. R. Scott for his assistance in the preparation of this manuscript.

\section{References}

1) Cartwright, R.D., Lloyd, S., Lilie, J. \& Kravitz, H. (1985) Sleep position training as treatment for sleep apnea syndrome: A preliminary study. Sleep, 8, 87-94.

2) Cummiskey, J., Williams, T.C., Krumpe, P.E. \& Guilleminault, C. (1982) The detection and quantification of sleep apnea by tracheal sound recordings. Am. Rev. Respir. Dis., 126, 221-224.

3) Fujita, S., Conway, W., Zorick, F. \& Roth, T. (1981) Surgical correction of anatomic abnormalities in obstructive sleep apnea syndrome: Uvulopalatopharyngoplasty. Otolaryngol. Head Neck Surg., 89, 923-934.

4) Gabriel, M., Witolla, C. \& Albani, M. (1978) Sleep and aminophylline treatment of apnea in preterm infants. Eur. $J$. Pediatr., 128, 145-149.

5) Gastaut, H., Tassinari, C.A. \& Druron, B. (1966) Polygraphic study of the episodic diurnal and nocturnal (hypnic and respiratory) manifestations of the Pickwick syn- 
drome. Brain Res., 2, 167-186.

6) Guilleminault, C., Tilpian, A. \& Dement, W.C. (1976) The sleep apnea syndromes. Ann. Rev. Med., 27, 465-484.

7) Harper, R.M. \& Sauerland, E.K. (1978) The role of the tongue in sleep apnea. In: Sleep Apnea Syndromes, edited by C. Guilleminault \& W.C. Dement, Liss., New York, pp. 219-234.

8) Hensley, M.J., Saunders, N.A. \& Strohl, K.F. (1980) Medroxyprogesterone treatment of obstructive sleep apnea. Sleep, 3, 441-446.

9) Krumpe, P. \& Cummiskey, J. (1980) Use of laryngeal sound recordings to monitor apnea. Am. Rev. Respir. Dis., 122, 797-801.

10) Mcevoy, R.D., Sharp, D.J. \& Thornton, A.T. (1986) The effects of posture on obstructive sleep apnea. Am. Rev. Respir. Dis., 133, 662-666.

11) Rechtschaffen, A. \& Kales, A. (1968) A manual of standardized terminology, techniques and scoring system for sleep stages of human subjects. National Institute of Health, Bethesda, MD.

12) Safar, P., Escarraga, L.S. \& Chang, F. (1959) Upper airway obstruction in the unconscious patient. J. Appl. Physiol, 14, 760-764.

13) Sullivan, C.E., Issa, F.G., Berthon-Jones, M. \& Eves, L. (1981) Reversal of obstructive sleep apnea by continuous positive airway pressure applied through the nares. Lancet, 1, 862-865.

14) Weitzman, E.D., Kahn, E. \& Pollak, C.P. (1980) Quantitative analysis of sleep and sleep apnea before and after tracheostomy in patients with the hypersomnia-sleep apnea syndrome. Sleep, 3, 407-424.

15) Wilson, S.L., Thach, B.T., Brouillette, R.T. \& Abu-Osba, Y.K. (1980) Upper airway patency in the human infant: Influence of airway pressure and posture. J. Appl. Physiol., 48, 500-504. 